\title{
TU/e EmonOWEN

\section{Influence of the embedded structure on the EFP formation of compact terminal sensitive projectile}

\section{Citation for published version (APA):}

Xing, B. Y., Liu, R. Z., Guo, R., Chen, L., Zhou, H., Yang, Y. L., \& Liu, L. (2017). Influence of the embedded structure on the EFP formation of compact terminal sensitive projectile. Defence Technology, 13(4), 310-315. https://doi.org/10.1016/j.dt.2017.05.006

\section{Document license:}

CC BY-NC-ND

DOI:

10.1016/j.dt.2017.05.006

Document status and date:

Published: 01/08/2017

\section{Document Version:}

Publisher's PDF, also known as Version of Record (includes final page, issue and volume numbers)

\section{Please check the document version of this publication:}

- A submitted manuscript is the version of the article upon submission and before peer-review. There can be important differences between the submitted version and the official published version of record. People interested in the research are advised to contact the author for the final version of the publication, or visit the $\mathrm{DOI}$ to the publisher's website.

- The final author version and the galley proof are versions of the publication after peer review.

- The final published version features the final layout of the paper including the volume, issue and page numbers.

Link to publication

\section{General rights}

Copyright and moral rights for the publications made accessible in the public portal are retained by the authors and/or other copyright owners and it is a condition of accessing publications that users recognise and abide by the legal requirements associated with these rights.

- Users may download and print one copy of any publication from the public portal for the purpose of private study or research.

- You may not further distribute the material or use it for any profit-making activity or commercial gain

- You may freely distribute the URL identifying the publication in the public portal.

If the publication is distributed under the terms of Article 25fa of the Dutch Copyright Act, indicated by the "Taverne" license above, please follow below link for the End User Agreement:

www.tue.nl/taverne

Take down policy

If you believe that this document breaches copyright please contact us at:

openaccess@tue.nl

providing details and we will investigate your claim. 


\title{
Influence of the embedded structure on the EFP formation of compact terminal sensitive projectile
}

\author{
Bo-yang Xing a , Rong-zhong Liu ${ }^{\text {a, }}{ }^{\text {, }}$, Rui Guo ${ }^{\text {a }}$, Liang Chen ${ }^{a}$, Hao Zhou ${ }^{\text {a, b }}$, \\ Yong-liang Yang a , Lei Liu ${ }^{\text {a, c }}$ \\ a School of Mechanical Engineering, Nanjing University of Science and Technology, Nanjing 210094, Jiangsu, China \\ ${ }^{\mathrm{b}}$ Faculty of Engineering, University of Nottingham, University Park, Nottingham NG7 2RD, UK \\ c Department of Mechanical Engineering, Eindhoven University of Technology, Eindhoven 5600MB, The Netherlands
}

\section{A R T I C L E I N F O}

\section{Article history:}

Received 16 January 2017

Received in revised form

17 April 2017

Accepted 17 May 2017

Available online 20 May 2017

\section{Keywords:}

Terminal sensitive projectile

Embedded structure

Detonation wave

EFP formation

\begin{abstract}
A B S T R A C T
To improve the damage efficiency of compact terminal sensitive projectile with EFP warhead, it is vital to understand how the embedded structure (ES) affects the EFP forming performance. In this paper, the corresponding numerical investigation is focused on, in which the fluid-structure interaction (FSI) method and the experimental verification are used. Based on the obtained quantitative relations between the forming performance and $\alpha$ (the ratio of height to maximum radius of ES), an optimal design is further provided. The results indicate that: when the embedded structural length and width range 0.1 $-0.3 \mathrm{D}$ and $0.1-0.2 \mathrm{D}$ (D: diameter of EFP warhead) at a fixed volume, respectively, EFP forming velocity nearly keeps as a constant, $1760 \mathrm{~m} / \mathrm{s}$; the height of ES has a dramatical effect on the propagating range of detonation wave, resulting in significant influence on the aerodynamic shape and length-to-diameter ratio of EFP; under the given constraints, the EFP length-diameter ratio can reach the optimal value 2.76, when the height of ES is 0.22D.
\end{abstract}

(๑) 2017 The Authors. Published by Elsevier Ltd. This is an open access article under the CC BY-NC-ND license (http://creativecommons.org/licenses/by-nc-nd/4.0/).

\section{Introduction}

The wave shaper is widely used in the explosively formed penetrator (EFP) warhead as an adjuster of detonation wave propagation. In detail, it makes the liner concentrate to the axial orientation and EFP form more easily [1,2] so as to achieve a penetrator with larger length-to-diameter ratio and compacted shape.

However, in the terminal sensitive projectile, the millimeterwave and infrared sensors are often used as ES directly for improving compactness [3,4]. The ES has the same effect on the propagation of detonation wave as the wave shaper does, but their size difference is significant. The ES usually has a relatively smaller diameter and larger axial thickness. In addition, their positions in the EFP warhead are different, where the ES is close to the geometric center of EFP warhead, while the wave shaper usually approaches to the back of EFP warhead [5]. In most cases, the ES decreases more charge space and affects its geometry significantly. As a result, the global forming performance of EFP warhead is weakened in some degree. For governing these negative influences,

\footnotetext{
* Corresponding author.

E-mail address: liurongz116@163.com (R.-z. Liu).

Peer review under responsibility of China Ordnance Society
}

it is necessary to understand how the ES influences the formation and the optimal embedded structural configuration is expected.

A lot of theoretical and simulation work has been done. Theoretical calculation and numerical simulation were used to study the influences of wave shaper and liner on EFP, and the relationship between the wave shaper and the liner configuration was studied to present a well-formed EFP matching relationship [6]. Li [7] pointed out that the ES can influence the shape of detonation wave. Zhang et al. [8] pointed out that the ES would enhance the crushing effect on the liner. Nurick et al. [9] pointed out that the change in explosive shape influenced the shape and depth of the shock front profile impinging upon the surfaces of the plates subjected to explosion loading via the detonation of plastic explosives.

At present, various methods can be used to investigate the EFP formation and the effect of the wave shaper on the propagation of detonation wave. But there has been little research on the effect of ES in the EFP warhead of compact terminal sensitive projectile on the detonation wave propagation and the EFP formation. AUTODYN-2D is adopted to consider the fluid-solid coupling problem $[10,11]$. The present paper uses AUTODYN ${ }^{\mathrm{TM}}$ to consider the fluid-solid coupling problem as well as analyze how the ES affects the propagation of detonation wave and the formation of EFP. 


\section{Numerical model}

\subsection{Material model}

A material model of air was derived from the material library in AUTODYNTM [12].

The material of liner is copper. The relation between the velocities of shock wave $D$ and material point $u$ can be approximated by Ref. [7]

$D=C_{1}+S_{1} u$

where $C_{1}$ is the adiabatic velocity of sound in the material; and $S_{1}$ is a coefficient. the values of each parameter are given in Table 1 [7]

The material constitutive relation for the copper is described by the Johnson-Cook equation [7].

$\sigma=\left(A+B \varepsilon^{n}\right)(1+C \ln \dot{\varepsilon})\left(1-\left|\frac{T-T_{r}}{T_{m}-T_{r}}\right|^{m}\right)$

where $A, B, C, n$ and $m$ are the parameters of material; $\varepsilon$ is the plastic strain; $\dot{\varepsilon}$ is the rate of plastic strain; $T_{\mathrm{m}}$ is the reference temperature; and $T_{\mathrm{r}}$ is the melting temperature of copper.

The material of a waveguide is aluminum. The main parameters of aluminum are shown in Table 2 [13].

The material of a shell is $45 \#$ steel. The main parameters of $45 \#$ steel are shown in Table 3 [7].

The material of an explosive is 8701. The equation of state (EOS) of explosive is chosen as JWL, the EOS is as follows [7]

$P=A\left|1-\frac{\omega}{R_{1} V}\right| e^{-R_{1} V}+B\left|1-\frac{\omega}{R_{2} V}\right| e^{-R_{2} V}+\frac{\omega E_{0}}{V}$

where $P$ is the shock wave pressure; $V$ is the volume ratio between detonation product and initial explosive; $A, B, R_{1}, R_{2}$ and $\omega$ are the parameters of material; $E_{0}$ is the specific internal energy of 8701 . The main parameters of 8701 are shown in Table 4 [7].

The material's name of ES is POLY-CARB. The main parameters of POLY-CARB are shown in Table 5 [7].

The material and EOS of each part of EFP warhead are shown in Table 6.

\subsection{Calculation model}

The finite element model is shown in Fig. 1, in which a detonation point is marked. The liner part is described by using Lagrangian framework when the shell, explosive, ES, waveguide and air are described by using Eulerian framework [7]. The mesh in the present paper used a regular cell with size of $0.5 \times 0.5 \mathrm{~mm} /$ cell [11], and the numerical results are grid independent.

In addition, the fluid-solid coupling algorithm is applied to catch the interaction between different parts. 2D axisymmetric model (about X-axis) is used for reducing the computation cost. The symmetrical inhibiting condition is added to the symmetrical surface of the model to restrict the displacement and rotation degrees of freedom of node $[14,15]$. And it is needed to add a flow boundary to the boundary of air in order to eliminate the influence of the waves reflected from an interface.

A typical ES is shown in Fig. 1, where $R_{1}$ is expressed as the top radius of ES, $R_{2}$ is expressed as the bottom radius, $H_{1}$ is expressed as the height of frustum of a cone, and $\mathrm{H}_{2}$ is expressed as the height of ES. The whole EFP warhead is placed in the air, the diameter and length of the warhead are $100 \mathrm{~mm}$, respectively; the thicknesses of bottom wall and circumferential wall of the EFP warhead are $5 \mathrm{~mm}$ and $4 \mathrm{~mm}$, respectively; the thickness and diameter of waveguide are $1 \mathrm{~mm}$ and $9 \mathrm{~mm}$, respectively; and the bottom of ES is $6 \mathrm{~mm}$ from the bottom of the explosive in the warhead.

\subsection{Numerical method verification}

The numerical method is first verified by redoing the case and performing the experimental case in Ref. [7]. Numerical model, experimental model and experimental layout are shown in Fig. 2 (a), (b) and (c), respectively.

The diameter of EFP warhead in Fig. 2 (b) is $155 \mathrm{~mm}$. The wooden support in Fig. 2 (b) is a supporting device when the EFP warhead is initiated. The function of wooden support is to minimize the influence of external force on EFP warhead during the initiation, and make the initiation state much more similar to the real scene where a terminal sensitive projectile EFP warhead initiates in the air, and the wooden support is used. The shape target in Fig. 2 (c) is used to measure the shape of EFP, and the velocity target in Fig. 2 (c) is used to measure the velocity of EFP.

The EFP sizes and velocities obtained by simulation and experimental measurement are compared in Fig. 3 and Table 7, respectively.

As shown in Fig. 3 and Table 7, the numerical results can meet the experimental results well, with relative difference of less than $10 \%$. Hence, it should be reasonable to apply the given numerical method to perform simulation.

\subsection{Numerical simulation scheme}

5 cases were designed to analyze the propagating range of detonation wave as keeping the volume of ES fixed, $R_{1}+H_{1}=0.15 D$ ( $D$ : diameter of EFP warhead), $R_{2}-R_{1}=0.08 D$, where $R_{1}$ is changed from $0.05 \mathrm{D}$ to $0.13 \mathrm{D}$, and $\alpha$ is defined as the value of $H_{2} / R_{2}$. The values of $\alpha$ and corresponding $R_{1}, H_{1}, R_{2}, H_{2}$ and the shape of ES are shown in Table 8.

\section{Results and discussion}

\subsection{Numerically simulated results}

The numerical results in Ref. [7] shows that the shape, structure and velocity of EFP are unchanged after $300 \mu$ s of detonation and that had been proved by experiments.

The length-diameter ratio $(l / d)$ of EFP is the ratio of the largest length of EFP to the largest diameter perpendicular to it.

Table 9 lists the velocity, $l / d$ and shape of EFP in different cases.

\subsection{Velocity and shape of EFP}

The velocities and shapes of EFP under different $\alpha$ are listed in Table 9. It can be found from Table 9 that the maximum velocity of EFP is obtained for $\alpha=1.5$, but the difference between the maximum $(1788 \mathrm{~m} / \mathrm{s})$ and minimum values $(1763 \mathrm{~m} / \mathrm{s})$ of EFP velocity is less than $1.5 \%$, so the effect of ES on the velocity of EFP can be ignored. Therefore, it can be deduced that the characteristic

Table 1

Main parameters of copper.

\begin{tabular}{|c|c|c|c|c|c|c|c|c|c|c|c|}
\hline$\rho /\left(\mathrm{g} \cdot \mathrm{cm}^{-3}\right)$ & $C_{1} /\left(\mathrm{m} \cdot \mathrm{s}^{-1}\right)$ & $S_{1}$ & G/GPa & A/MPa & $B / \mathrm{MPa}$ & $n$ & $C$ & $m$ & $\gamma_{0}$ & $T_{\mathrm{m}} / \mathrm{K}$ & $T_{\mathrm{r}} / \mathrm{K}$ \\
\hline 8.93 & 3940 & 1.489 & 46 & 0.09 & 0.292 & 0.31 & 0.025 & 1.09 & 2.02 & 1356 & 293 \\
\hline
\end{tabular}


Table 2

Main parameters of aluminum.

\begin{tabular}{|c|c|c|c|c|c|c|c|c|c|c|c|}
\hline$\rho /\left(\mathrm{g} \cdot \mathrm{cm}^{-3}\right)$ & $C_{1} /\left(\mathrm{m} \cdot \mathrm{s}^{-1}\right)$ & $S_{1}$ & $\mathrm{G} / \mathrm{GPa}$ & $A / \mathrm{MPa}$ & $B / \mathrm{MPa}$ & $n$ & $C$ & $m$ & $\gamma_{0}$ & $T_{m} / \mathrm{K}$ & $T_{\mathrm{r}} / \mathrm{K}$ \\
\hline 2.785 & 5328 & 1.338 & 27.6 & 0.265 & 0.426 & 0.34 & 0.015 & 1 & 2 & 775 & 293 \\
\hline
\end{tabular}

Table 3

Main parameters of $45 \#$ steel.

\begin{tabular}{|c|c|c|c|c|c|c|c|c|c|c|c|}
\hline$\rho /\left(\mathrm{g} \cdot \mathrm{cm}^{-3}\right)$ & $C_{1} /\left(\mathrm{m} \cdot \mathrm{s}^{-1}\right)$ & $S_{1}$ & G/GPa & $A / \mathrm{MPa}$ & $B / \mathrm{MPa}$ & $n$ & $C$ & $m$ & $\gamma_{0}$ & $T_{m} / K$ & $T_{\mathrm{r}} / \mathrm{K}$ \\
\hline 7.84 & 4570 & 1.49 & 80 & 0.5 & 0.32 & 0.28 & 0.064 & 1.06 & 1.93 & 1790 & 293 \\
\hline
\end{tabular}

Table 4

Main parameters of 8701 .

\begin{tabular}{|c|c|c|c|c|c|c|c|}
\hline $\begin{array}{l}\rho \\
/\left(\mathrm{g} \cdot \mathrm{cm}^{-3}\right)\end{array}$ & $A / 10^{8} \mathrm{kPa}$ & $B / 10^{8} \mathrm{kPa}$ & $R 1$ & $R 2$ & $\omega$ & $\mathrm{D} / 10^{3}\left(\mathrm{~m} \cdot \mathrm{s}^{-1}\right)$ & $E_{0} / 10^{6}\left(\mathrm{~kJ} \cdot \mathrm{m}^{-3}\right)$ \\
\hline 1.70 & 8.54 & 6.2049 & 4.60 & 1.35 & 0.25 & 8.315 & 8.5 \\
\hline
\end{tabular}

Table 5

Main parameters of POLY-CARB.

\begin{tabular}{lllllll}
\hline$\rho$ & $C_{1} /\left(\mathrm{m} \cdot \mathrm{s}^{-1}\right)$ & $S_{1}$ & $G / 10^{5} \mathrm{kPa}$ & $A / 10^{4} \mathrm{kPa}$ & $\gamma_{0}$ & $T_{\mathrm{r}} / \mathrm{K}$ \\
\hline 1.7 & 1933 & 2.65 & 10.0 & 8.06 & 0.61 & 293 \\
\hline
\end{tabular}

Table 6

Materials and EOSs of the parts of EFP warhead.

\begin{tabular}{lll}
\hline Part & Material & EOS \\
\hline Air & Air & Ideal Gas \\
Liner & Copper & Shock \\
Waveguide & Aluminum & Shock \\
Shell & $45 \#$ steel & Shock \\
Explosive & 8701 & JWL \\
ES & POLY-CARB & Shock \\
\hline
\end{tabular}

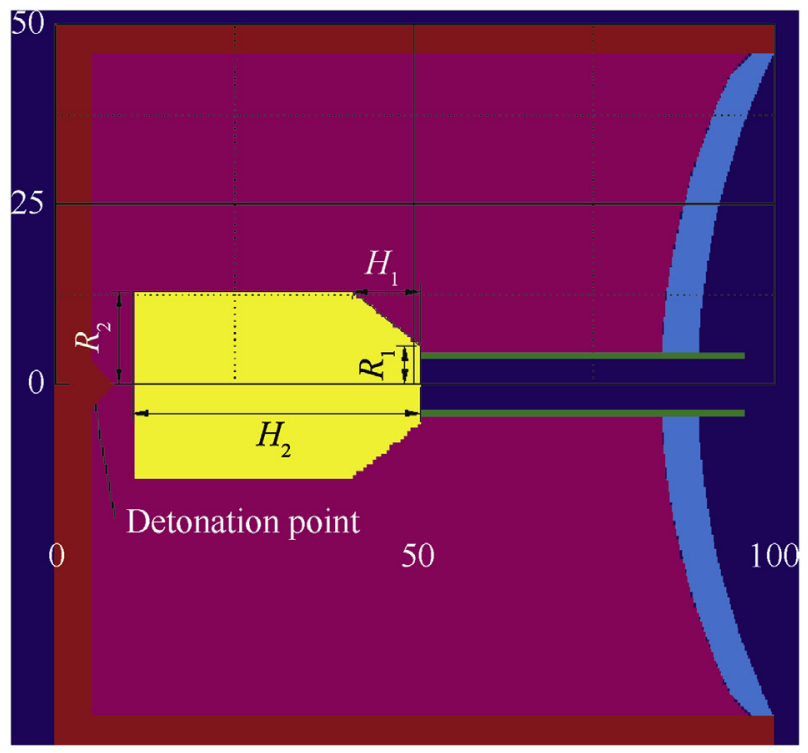

Fig. 1. Finite element model of a typical ES used in terminal sensitive projectile (unit: $\mathrm{mm})$.

parameter of $\alpha$ discussed in the present paper has little effect on the velocity of EFP when the ES consists of cylinder and frustum of a cone and the volume of ES is fixed. This is because the main factors affecting the velocity of EFP, such as the sort and mass of charge, the configuration, size and material of liner, the material and thickness of warhead shell, were not changed. It can be found that the tail of EFP will be greatly affected by the characteristic parameter of $\alpha$ when the ES consists of the cylinder and frustum of a cone and the volume of ES is fixed. With the decrease in $\alpha$, the ES is flattened, and the detonation wave propagating through the ES gradually changes from a spherical wave to a planar wave. As a result, the detonation wave changes the aerodynamic shape of the EFP tail. With the decrease in $\alpha$, a pit gradually appears in the EFP tail firstly, and then a hump gradually appears, finally a hump gradually disappears. The shape of EFP in Case 2 is ideal, the pit in the EFP tail can effectively improve the aerodynamic shape of EFP and reduce the loss of velocity of EFP, thereby enhancing the combat effectiveness.

\subsection{Length-diameter ratio of EFP}

The $l / d$ and shape of EFP under different $\alpha$ are shown in Fig. 4.

It can be found from Fig. 4 that the largest $l / d$ is 2.76 for $\alpha=1.5$, and the difference among the other cases is below 5\%. Comparing with the propagation and pressure field of detonation wave in Case 2 is more compact. As a result, the more uniform pressure field makes the final EFP forming more satisfactory, with greater lengthdiameter ratio and better combat effectiveness.

\subsection{Comparative analysis of detonation wave propagation}

In order to characterize the propagation process of detonation wave, the simulated results within $10 \mu$ s after detonation are recorded. And the pressure contour plots of detonation wave propagation process in different cases are shown in Table 10. The variable $t$ in Table 10 represents the time after detonation.

Through the comparison of detonation wave propagation process in Table 10, it can be found that the propagating range and pressure field of detonation wave are almost the same for $t=2 \mu \mathrm{s}$. Furthermore, the propagating range and pressure field of detonation wave in ES are closely related to the value of $R_{1}$, specifically when the value of $R_{1}$ is smaller than the diameter of the detonation front, the propagating range and pressure field of detonation wave inside and outside of ES will be clearly demarcated. When the value of $R_{1}$ increases to be equal to the diameter of detonation front, the boundary distinguishing the propagating range of detonation wave and the boundary distinguishing the pressure fields inside and outside of the ES begins to fade. But ES has an obvious obstructive 

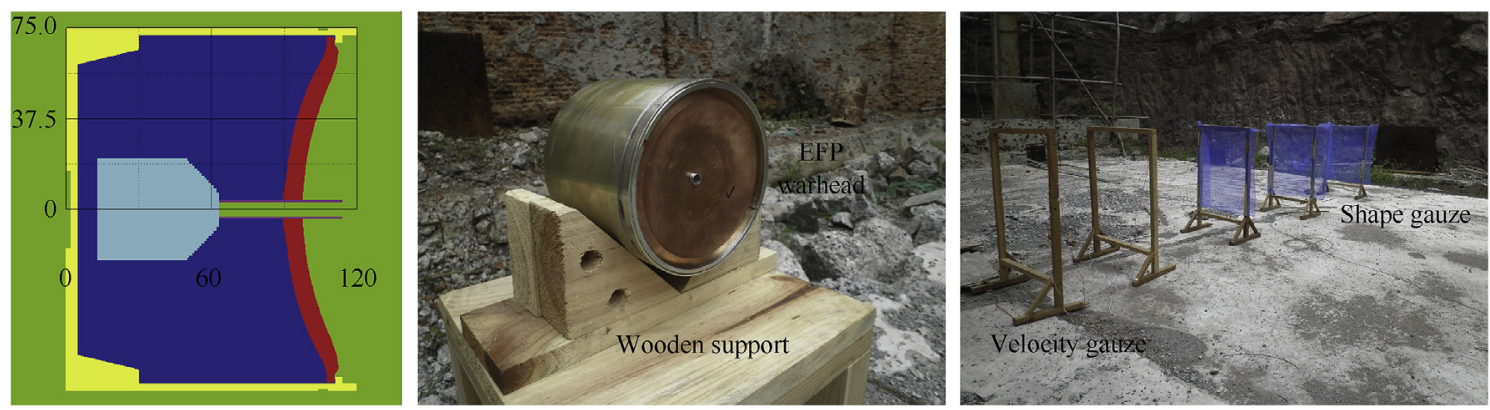

Fig. 2. Numerical model (a), experimental model (b) and experimental layout (c) (unit: mm).
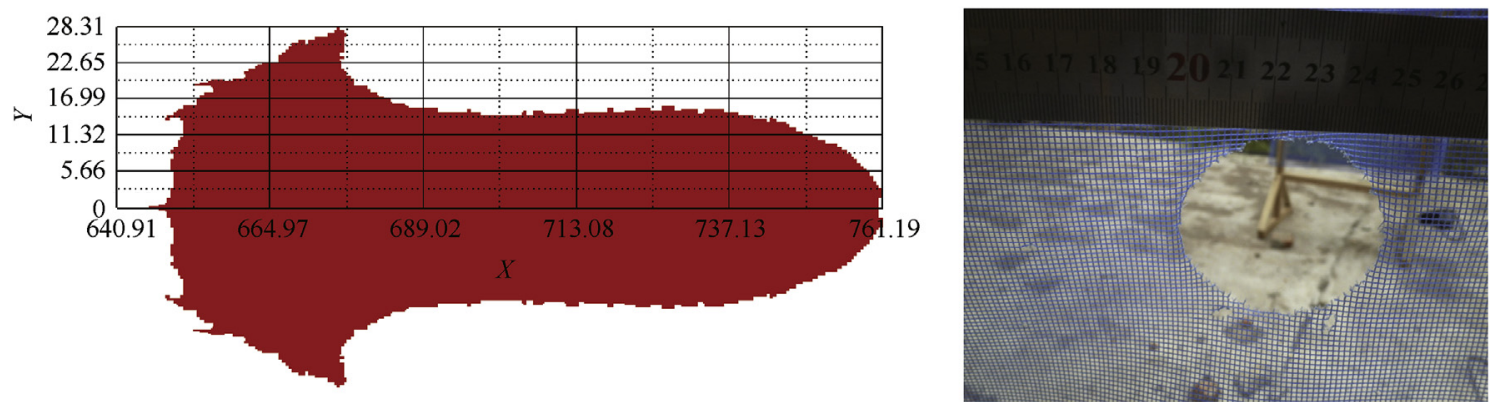

Fig. 3. The diameter of EFP in simulation and result of the shape target (unit in left: $\mathrm{mm}$, unit in right: $\mathrm{cm}$ ).

Table 7

The diameter and velocity of EFP in experiment and simulation.

\begin{tabular}{lll}
\hline & Diameter $/ \mathrm{mm}$ & Velocity $/\left(\mathrm{m} \cdot \mathrm{s}^{-1}\right)$ \\
\hline Experiment & 54 & 1621 \\
Simulation & 56.62 & 1732 \\
Difference rate & $4.9 \%$ & $6.8 \%$ \\
\hline
\end{tabular}

effect on the propagating range of detonation wave.

When $t=4 \mu$ s, the propagation patterns of wave in different cases become significantly different. The propagating range of detonation wave increases with the decrease in $\alpha$. The reason is that the length of ES along the central axis of warhead decreases with the decrease in $\alpha$; and then the obstructive effect of ES on the

Table 8

The values of $\alpha$ and corresponding $R_{1}, H_{1}, R_{2}, H_{2}$ and the shape of ES.

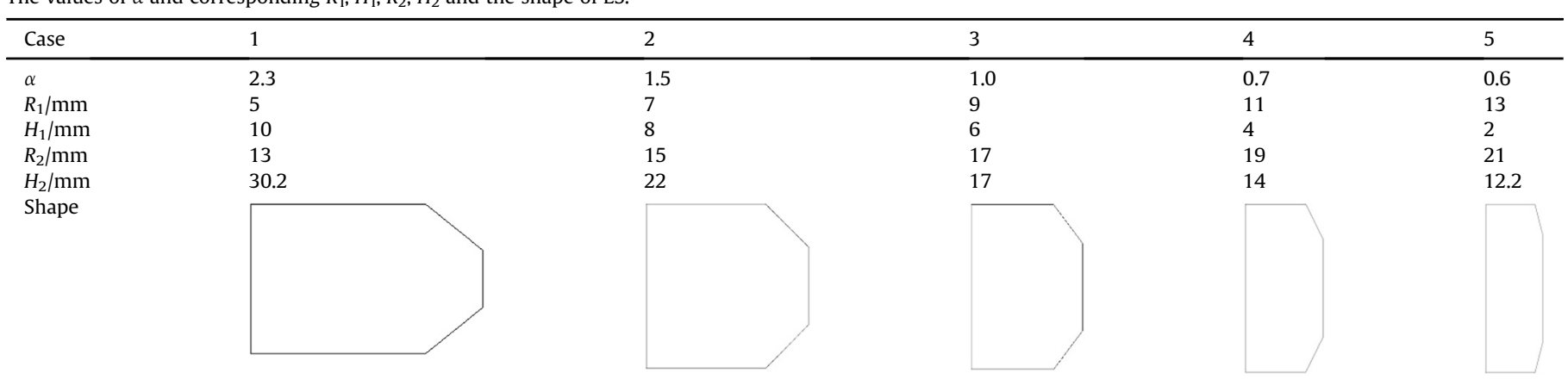

Table 9

Comparison of the velocity, $l / d$ and the shape of EFP in different cases.

\begin{tabular}{|c|c|c|c|c|c|}
\hline Case & 1 & 2 & 3 & 4 & 5 \\
\hline$\alpha$ & 2.3 & 1.5 & 1.0 & 0.7 & 0.6 \\
\hline$v /\left(\mathrm{m} \cdot \mathrm{s}^{-1}\right)$ & 1763 & 1788 & 1766 & 1767 & 1764 \\
\hline$l / d$ & 2.52 & 2.76 & 2.43 & 2.53 & 2.40 \\
\hline Shape & & 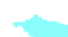 & & & \\
\hline
\end{tabular}




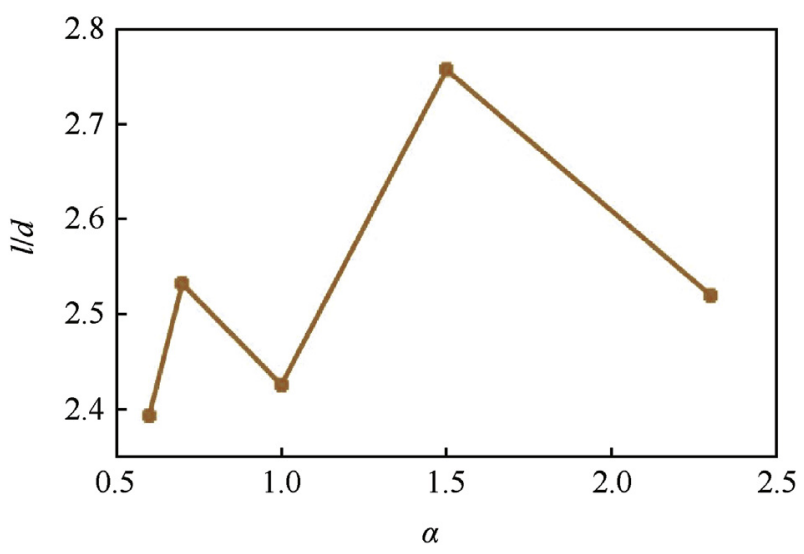

Fig. 4. The $l / d$ and shape of EFP under different $\alpha$.

propagating range along the central axis of warhead gradually decreases. As a result, the detonation wave can pass through the ES and propagate to a wider range. The influence of ES on the high- pressure shock waves range in the front of the detonation wave becomes smaller with the decrease of $\alpha$. The ES has no effect on the detonation wave that does not go through the ES so the propagating range and pressure field of detonation wave are unchanged. It indicates that the ES can hinder the detonation wave from propagating, and the hindering effect fades as the length of ES in the propagating direction of detonation wave decreases.

When $t=6 \mu \mathrm{s}$, the propagating range of detonation wave is basically the same in different cases. The reason is that the highpressure shock waves in the front of detonation wave has already crossed over the ES, thus the ES has no effect on the high pressure range in the front of detonation wave. However, the detonation pressure field varies greatly depending on the configurations of ES. It can be judged that the ES has an obstructive effect on the detonation wave still propagating in the ES. It can also be found from the pressure contour plot that the ES causes a pressure concentration during propagating of detonation wave, and this concentration is closely related to the value of $\mathrm{H}_{2}$. With the decrease in $\mathrm{H}_{2}$, the concentration of pressure in the propagating range of detonation wave starts to appear gradually, and the concentrated position is continually getting closer to the high-pressure range in the front of

\section{Table 10}

The pressure contour plots of detonation wave propagation in different cases.

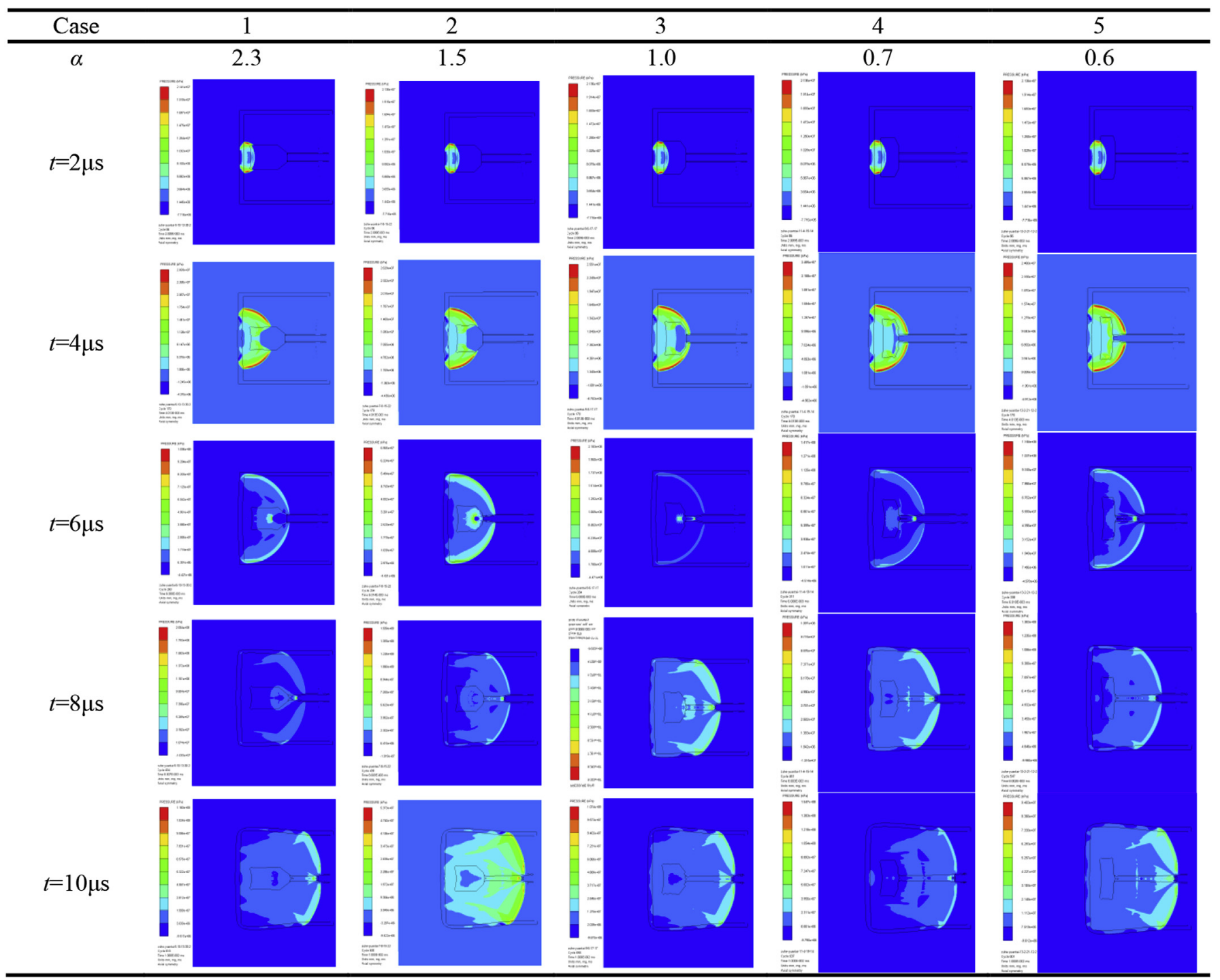


the detonation wave propagating range.

When $t=8 \mu \mathrm{s}$, the propagating range of detonation wave is basically the same in different cases. However, the detonation pressure field varies with different values of $\alpha$. With the decrease in $\alpha$, the high-pressure range in the front of the propagating range of detonation wave tends to expand. The shape of the high-pressure range in the front of the propagating range of detonation wave is quite different, which can be found from the pressure contour plot with different values of $\alpha$. The reason is that the detonation wave in the ES was propagated outside of the ES, combined with the detonation wave that propagated outside of the ES, and its propagating range is wider. In the propagating range of detonation wave, the plane wave begins to appear with the decrease in $\alpha$, for $\alpha=0.7$. And this kind of plane wave is formed by the detonation wave passing through the ES. The smaller the value of $\alpha$ is, the more obvious the outline of the plane wave is, which corresponds to the conclusion in Ref. [6].

When $t=10 \mu \mathrm{s}$, the propagating range of detonation wave is basically the same in different cases. But the pressure field of detonation wave and the outline of high-pressure range in the front of the detonation wave propagating range vary greatly depending on the values of $\alpha$. It can be found from the pressure contour plot that the outline of detonation wave passing through the ES is quite different obviously for different values of $\alpha$. With the decrease in $\alpha$, the detonation wave passing through the ES gradually changes from a spherical wave to a planar wave, and the outline of the planar wave is very obvious when $\alpha=0.7$ and $t=10 \mu \mathrm{s}$. It indicates that the values of $\alpha$ have a great influence on the propagation of detonation wave that passes through the ES. And it is believed that the detonation influenced by $\alpha$ of ES may be one of the most important reasons for the different tail shape of EFP in the final result.

\section{Conclusions}

1) When the ES made of POLY-CARB material consists of cylinder and frustum of a cone and the volume of ES is fixed, the values of $\alpha$ discussed above have little effect on the velocity of EFP. The disparities among the velocities in different cases are neglectable because the main factors affecting the velocity of EFP, such as the sort and mass of charge, the configuration, size and material of liner, the material and thickness of warhead shell, are not changed.

2) When the ES made of POLY-CARB material consists of cylinder and frustum of a cone and the volume of ES is fixed, there exists the best tail shape of EFP among the values of $\alpha$ discussed above. With the decrease in the value of $\alpha$, the detonation wave passing through the ES gradually changes from spherical wave to planar wave, where exists a proper shape of the wave which can make a pit in the tail of EFP and it is the best tail shape of EFP. Therefore, a proper value of $\alpha$ of ES can be used to make an effective use of the detonation wave, get a more reasonable aerodynamic-shaped EFP, and effectively improve the combat effectiveness.

3) In the early stage of initiation, the ES can decrease the velocity of detonation wave that go through the ES, so the detonation pressure field become different. The detonation pressure field is different under different $\alpha$, but the quantitative relationship needs to be explored in further work.

\section{Acknowledgement}

The work presented in this paper has been funded by the National Natural Science Foundation of China under No. 11102088, Fundamental Research Funds for the Central Universities under No. 30915118821, and funded by the Specialized Research Fund for the Doctoral Program of Higher Education of China under No. 20133219110019.

\section{References}

[1] R. Fong, W. Ng, K. Weimann. Nonaxisymmetric waveshaped EFP warheads[C]. 20th International Symposium on Ballistics, Orlando, FL, USA, 2002: 585-588.

[2] David Bender, Richard Fong, William Ng, et al. Dual mode warhead technology for future smart Munitions[C]. 19th International Symposium on Ballistics, Interlaken, Switzerland, 2001:679-684.

[3] Jianbing Men, Jianwei Jiang, Jian Luo. Numerical simulation research on the influence of sensing elements on EFP forming [J]. Chin J Ballist 2005;17(1): 69-71 [in Chinese].

[4] Chou PC, Carleone J, Flis WJ, et al. Improved formulas for velocity, acceleration, and projection angle of explosively driven liners [J]. Propellants Explos Pyrotech 1983;8(6):175-83.

[5] Gang Li, Liu Rongzhong, Guo Rui, Zhang Li. Eccentric liner in the amelioration of EFP warhead design with embedded feed structure [J]. Chin J High Press Phys 2015;12:436-42 [in Chinese].

[6] Chuansheng Zhu. Research on the forming technology of the warhead with the diaphragm explosion [D]. Nanjing University of Science and Technology; 2014 [in Chinese].

[7] Gang LI. Technology research on the compact EFP warhead of terminal sensitive projectile [D]. Nanjing University of Science and Technology; 2013 [in Chinese].

[8] Zhang BZ, Xu LT, Wang ZH, et al. Experimental and numerical study on the forming and penetration properties of explosively-formed projectile[J]. Ordnance Material Sci Eng 2012;35(4):37-9 [in Chinese].

[9] Nurick GN, Mahoi S, Langdon GS. The response of plates subjected to loading arising from the detonation of different shapes of plastic explosive [J]. Int J Impact Eng 2016;89:102-13.

[10] Wu J, Liu J, Du Y. Experimental and numerical study on the flight and penetration properties of explosively-formed projectile [J]. Int J impact Eng 2007;34(7):1147-62.

[11] Xiao QQ Huang ZX, Zu XD, et al. Penetration research of jacketed jet into concrete[J]. Int J Impact Eng 2013;54:246-53.

[12] Rogers GFC, Mayhew YR. Thermodynamic and transport properties of fluids [M]. Blackwell; 1995.

[13] Johnson \& Cook. Selected hugoniots: EOS [C] 7th international symposium on ballistics may 1 1969. LA-4167-MS.

[14] Johnson GR. Dynamic analysis of explosive-metal interaction in three dimensions. J Appl Mech 1981;103:30-4.

[15] Johnson GR, Stryk RA. Some considerations for 3D EFP computations [J]. Int ] impact Eng 2006;32(10):1621-34. 